\title{
Internal Metal(loid)s Are Potentially Involved in the Association Between Ambient Fine Particulate Matter and Blood Pressure: A Repeated-Measurement Study in North China
}

\section{Changxin Lan}

Institute of Reproductive and Child Health, Peking University

Qi Li

Jiangxi Environment Engineering Vocational College

Bin Wang ( $\sim$ binwangpku@foxmail.com)

Institute of Reproductive and Child health, Peking University https://orcid.org/0000-0002-1164-8430

Tao Xue

Peking University Health Science Centre

Junxi Chen

Peking University Health Science Centre

Bahabieke Jiangtulu

Peking University Health Science Centre

Shufang Ge

School of Environment, Beijing Normal University

\section{Xuepeng Wang}

School of Environment, Beijing Normal University

\section{Miaomiao Gao}

School of Environment, Beijing Normal University

\section{Yanxin Yu}

School of Environment, Beijing Normal University

\section{Ying $\mathrm{Xu}$}

Department of Building Science, Tsinghua University

\section{Xiuge Zhao}

Chinese Research Academy of Environmental Science

\section{Zhiwen Li}

Institute of Reproductive and Child Health, Peking University

\section{Research}

Keywords: Fine particulate matter, blood pressure, childbearing age women, trace elements, serum

Posted Date: July 7th, 2020 
DOI: https://doi.org/10.21203/rs.3.rs-40413/v1

License: (c) (P) This work is licensed under a Creative Commons Attribution 4.0 International License. Read Full License

Version of Record: A version of this preprint was published at Chemosphere on March 1st, 2021. See the published version at https://doi.org/10.1016/j.chemosphere.2020.129146. 


\section{Abstract}

Background The effects of ambient fine particulate matter (PM 2.5) exposure on blood pressure have been widely reported. However, there remains uncertainty regarding the underlying roles of particulate matter components. We aimed to investigate the association between ambient PM 2.5 exposure and blood pressure, as well as the potential mediating effects of trace metal(loid)s, in a repeated-measurement study that enrolled women of childbearing age. Methods Our study included 35 participants from Hebei Province, China, each of whom was visited five times. During each visit, questionnaire surveys were conducted, blood pressure was measured, and blood was collected. The daily PM 2.5 exposure for all participants was estimated according to their residential addresses using a spatiotemporal model that combined monitoring data with satellite measurements and chemical-transport model simulations. This model was used to calculate average PM 2.5 concentrations $1,3,7,15,30$, and 60 days prior to each visit. Serum concentrations of various trace metal(loid)s were measured using an inductively coupled plasma-mass spectrometer. A linear mixed-effects model was used to investigate associations among study variables. Results PM 2.5 concentration was positively associated with both systolic and diastolic blood pressures, with or without adjustments for potential confounders. Likewise, PM 2.5 concentration was positively associated with serum concentrations of manganese and arsenic, and negatively associated with serum concentrations of nickel, tin, and chromium. Only the serum concentration of molybdenum was negatively associated with systolic blood pressure. Conclusion Ambient PM 2.5 exposure may contribute to elevated blood pressure, potentially by interfering with internal metal(loid) intake in the human body.

\section{Background}

Ambient fine particulate matter $\left(\mathrm{PM}_{2.5}\right)$ was ranked as the fifth global mortality risk factor in 2015 [1] and is an important risk factor for cardiovascular and cardiopulmonary diseases [2, 3]. Many studies have reported that that ambient $\mathrm{PM}_{2.5}$ exposure can elevate blood pressure $[4,5,6]$, thereby increasing the risk of hypertension $[7$, 8]. $\mathrm{PM}_{2.5}$ is mainly composed of various inorganic constituents $[9,10,11]$. Of these, the roles of various trace metal(loid)s in blood vessel injuries or the development of hypertension are of public concern $[12,13,14]$ and are the focus of ongoing research.

Results from epidemiological surveys and experimental studies indicate that toxic metal(loid)s such as arsenic (As), cadmium, and lead $(\mathrm{Pb})$ can elevate blood pressure $[15,16,17]$. In addition, the relationship between the intake of essential trace elements and blood pressure has been widely studied at the population level; however, the dose-response relationships are complicated $[18,19,20]$, due to challenges in maintaining blood pressure within a certain range. Likewise, the influences of various metal(loid)s on blood vessel injuries depend on individual intake levels, as well as interaction effects among metal(loid)s. Generally, greater exposure to toxic metal(loid)s or disturbance in the balance of essential trace elements in the human body can lead to adverse effects on blood pressure stability. Elevated $\mathrm{PM}_{2.5}$ exposure has been shown to induce systemic injuries via oxidative stress and inflammation pathways [21, 22], in which various metal(loid)s are involved [23, 24]. Although population studies have been conducted, there remains a lack of clarity regarding whether $\mathrm{PM}_{2.5}$ affects blood pressure by interfering with the internal balance of metal(loid)s in the human body. 
To the best of our knowledge, there have been few studies regarding the relationships of population $\mathrm{PM}_{2.5}$ exposure with internal metal(loid) levels. A study conducted in Shanxi Province, China, revealed that long-term indoor air pollution was closely related to toxic-element exposure and essential trace elements in hair [12]. However, this study had several limitations, as it used a cross-sectional study design without follow-up validation. Another study showed that the concentration of chromium (Cr) in $\mathrm{PM}_{2.5}$ was positively correlated with the concentration in urine [25]. Therefore, our study aimed to investigate the relationship between ambient $\mathrm{PM}_{2.5}$ concentration and blood pressure, as well as the potential involvement of various serum toxic metal(loid)s and essential trace elements, in a population of women of childbearing age in northern China.

\section{Methods}

\section{Population Recruitment}

This study was carried out in the Mancheng District of Baoding City in Hebei Province, China. Women were invited to join the study if they met the following inclusion criteria: 1) they were local residents who had resided in the district for at least 2 years; 2) they were aged 18 to 50 years old; and 3) they had no history of cardiovascular disease, hepatitis, cancer, diabetes, rheumatoid arthritis, chronic renal failure, or chronic lung disease. The first visit took place in January 2015, with four follow-up visits conducted in March 2015, June 2015, January 2016, and April 2016. During each visit, questionnaire surveys were conducted, blood pressure was measured, and blood was collected. Each participant rested for more than $5 \mathrm{~min}$; their blood pressure was measured twice using an electronic manometer (OMRON, Japan), and the value of the second measurement was recorded for analysis. When measurements appeared questionable, a mercury sphygmomanometer was used for confirmation. Questionnaire surveys were used to obtain information regarding each participant's height, weight, age, residence, occupation, educational background, smoking status, passive smoking status, frequency of alcohol consumption (wine or beer), and exercise habits. In total, 35 women (157 person-visits) were included in this study, following exclusion of women who were visited fewer than three times. Our study protocol was approved by the institutional review board of Peking University, and written informed consent was obtained from all participants.

\section{Quantification of Serum Metal(loid)s}

Fasting blood samples were collected by healthcare workers. Serum from each sample was then immediately divided into several screw-top vials and stored at $-80^{\circ} \mathrm{C}$ to reduce the need for repeated freeze-thaw cycles before analysis. Serum concentrations of copper (Cu), zinc ( $\mathrm{Zn})$, manganese (Mn), iron (Fe), cobalt (Co), nickel $(\mathrm{Ni})$, molybdenum (Mo), selenium (Se), tin ( $\mathrm{Sn})$, chromium ( $\mathrm{Cr}$ ), lead (Pb), arsenic (As), and cadmium (Cd) were measured using inductively coupled plasma-mass spectrometry (ICP-MS; ELAN DRC II, PerkinElmer, USA). Standard serum samples (ClinChek® Serum Control, Level II; RECIPE GmbH, Germany) were used for quality control. The limits of detection of the metal(loid)s of interest were $0.60 \mathrm{ng} / \mathrm{mL}(\mathrm{Cu}), 1.20 \mathrm{ng} / \mathrm{mL}(\mathrm{Zn})$, $0.16 \mathrm{ng} / \mathrm{mL}(\mathrm{Mn}), 18.00 \mathrm{ng} / \mathrm{mL}$ (Fe), $0.02 \mathrm{ng} / \mathrm{mL}$ (Co), $0.10 \mathrm{ng} / \mathrm{mL}$ (Ni),0.04 ng/mL (Mo), $1.00 \mathrm{ng} / \mathrm{mL}$ (Se), 0.14 ng/mL (Sn), 0.04 ng/mL (Cr), 0.05 ng/mL (Pb), 1.00 ng/mL (As), and 0.06 ng/mL (Cd). Quantitative analyses were conducted at the Central Laboratory of Biological Elements in the Peking University Health Science Center, and experiments were conducted in accordance with China Metrology Accreditation protocols.

\section{Ambient PM2.5 Concentrations}


The daily distributions of $\mathrm{PM}_{2.5}$ were estimated using a well-established data fusion model [26] that combines monitoring values with satellite remote-sensing measurements and simulations from a chemical-transport model. These estimates agree well with ground surface monitoring observations and cover a robust spatiotemporal range. Based on the home addresses of the 35 women, ambient $\mathrm{PM}_{2.5}$ exposures were estimated for each woman. The average $\mathrm{PM}_{2.5}$ concentrations at $1,3,7,15,30$, and 60 days prior to each visit day (i.e., the "lag time") were denoted as Lag-1, Lag-3, Lag-7, Lag-15, Lag-30, and Lag-60, respectively.

\section{Data Analyses}

Means, medians, interquartile ranges (IQRs), standard deviations, and minimum and maximum values were used to describe the data distributions. The associations between dependent variables $(Y$ ) and target independent variables $\left(X_{\mathrm{T}}\right)$ of concern were analyzed using a linear mixed-effects model, which included a random intercept for each participant to adjust for within-subject correlations due to repeated measurements. Two models ("Model-I" and "Model-II") were used to examine the relationships between PM $_{2.5}$ and blood pressure, $\mathrm{PM}_{2.5}$ and serum metal(loid)s, and serum metal(loid)s and blood pressure. In addition, considering the effects of ambient temperature on blood pressure, Model-IIl was used to investigate the relationship between $\mathrm{PM}_{2.5}$ and blood pressure. The components of each model were as follows:

\begin{tabular}{|lll|}
\hline Model-I: & $Y=\beta_{1} \times X_{\mathrm{T}}+\gamma(S)$ \\
\hline Model-II: & $Y=\beta_{1} \times X_{\mathrm{T}}+\beta_{2-11} \times C F_{1-10}+\gamma(S)$ \\
\hline Model-III: & $Y=\beta_{1} \times X_{\mathrm{T}}+\beta_{2-12} \times C F_{1-11}+\gamma(S)$ \\
\hline
\end{tabular}

The three models incorporated fixed terms with coefficients of $\beta_{1}$ for $X_{\mathrm{T}}$ and $\beta_{2-12}$ for potential confounders ( $C F_{1}$ - 10; i.e., age, body mass index, location, occupation, education, smoking status, passive smoking status, alcohol consumption, and exercise; $C F_{11}$, ambient temperature), as well as a random intercept for each participant, $\gamma(S)$. The change in blood pressure $(\mathrm{mmHg})$ was calculated for every $10 \mu \mathrm{g} / \mathrm{m}^{3}$ increase in $\mathrm{PM}_{2.5}$. Metal(loid) concentrations were $\log _{10}$-transformed to meet normality assumptions in analyses of the associations between $\mathrm{PM}_{2.5}$ and serum metal(loid)s. The percentage change $(P C)$ in each metal(loid) per IQR increase in mean $\mathrm{PM}_{2.5}$ concentration was calculated as follows:

$$
\mathrm{PC}=\left[10^{\mathrm{IQR}\left(\mathrm{PM}_{2.5}\right) \times \beta_{1}-1}\right] \times 100 \backslash \%
$$

4

The associations between serum metal(loid)s and blood pressure were expressed as absolute changes in blood pressure ( $\mathrm{mmHg}$ ) per IQR increase in each metal(loid). A value of $P<0.05$ (two-sided) was considered to indicate statistical significance. All statistical analyses were performed using R software (v. 3.6.2; R Core Team 2019).

\section{Results}

\section{Population Characteristics}


In total, 35 women were included in our study. Among them, 21 (60\%), 10 (29\%), and 4 (11\%) women were visited five, four, and three times, respectively. The participants all belonged to the Han ethnic group;

approximately half of them lived in rural areas. The overall mean (standard deviation) age and body mass index were 35.3 (6.5) years and $24.3(3.2) \mathrm{kg} / \mathrm{m}^{2}$, respectively. Few participants (2\%) were active smokers, but a relatively large proportion experienced passive smoking (42\%). Most participants did not drink white wine, whereas $30 \%$ drank beer (less than once per week). In terms of educational background, approximately $77 \%$ completed high school. Most of the participants were technicians (45\%) or factory workers (22\%). Data regarding population characteristics were captured for all participants, except for $4 \%$ of the participants with regard to passive smoking status (Table 1 ). 
Table 1

Population characteristics of the 35 women recruited during the five visits in North China

\begin{tabular}{|c|c|c|c|c|c|c|}
\hline & \multicolumn{6}{|l|}{ Visit time } \\
\hline & $1 \mathrm{st}$ & 2nd & 3rd & 4th & 5th & Overall \\
\hline No. of subjects & 33 & 35 & 32 & 25 & 32 & 157 \\
\hline Age (years) & $35.0(6.5)^{a}$ & $34.9(6.5)$ & $35.5(6.5)$ & $35.4(7.0)$ & $35.8(6.4)$ & $35.3(6.5)$ \\
\hline BMI $\left(\mathrm{kg} / \mathrm{m}^{2}\right)$ & $24.4(3.3)$ & $24.3(3.3)$ & $24.3(3.1)$ & $24.6(3.1)$ & $24.1(3.2)$ & $24.3(3.2)$ \\
\hline \multicolumn{7}{|l|}{ Location } \\
\hline Rural & $16(48)^{b}$ & 17(49) & $17(53)$ & $14(56)$ & $15(47)$ & $79(50)$ \\
\hline County & $17(52)$ & $18(51)$ & $15(47)$ & $11(44)$ & 17(53) & $78(50)$ \\
\hline \multicolumn{7}{|l|}{ Occupation } \\
\hline Farmer & $5(15)$ & $5(14)$ & $5(16)$ & $5(20)$ & $6(19)$ & $26(17)$ \\
\hline Worker & $8(24)$ & $8(23)$ & $7(22)$ & $6(24)$ & $6(19)$ & $35(22)$ \\
\hline Technician & $14(42)$ & $16(46)$ & $14(44)$ & $10(40)$ & 17(53) & $71(45)$ \\
\hline $\begin{array}{l}\text { Business and } \\
\text { Service }\end{array}$ & $5(15)$ & $5(14)$ & $5(16)$ & $3(12)$ & $3(9)$ & 21(13) \\
\hline Others & $1(3)$ & $1(3)$ & $1(3)$ & $1(4)$ & $0(0)$ & $4(3)$ \\
\hline \multicolumn{7}{|l|}{ Education } \\
\hline $\begin{array}{l}\text { Primary School } \\
\text { or below }\end{array}$ & $1(3)$ & $1(3)$ & $1(3)$ & $1(4)$ & $1(3)$ & $5(3)$ \\
\hline Junior middle & $7(21)$ & $7(20)$ & $6(19)$ & $5(20)$ & $6(19)$ & $31(20)$ \\
\hline \multicolumn{7}{|l|}{ school } \\
\hline High school & 18(55) & $18(51)$ & 17(53) & 13(52) & $16(50)$ & $82(52)$ \\
\hline \multicolumn{7}{|c|}{ a Data are presented as the mean (standard deviation). } \\
\hline \multicolumn{7}{|c|}{ b Data are presented as the number of subjects (percentage). } \\
\hline
\end{tabular}




\begin{tabular}{|c|c|c|c|c|c|c|}
\hline & Visit time & & & & & \\
\hline College or above & $7(21)$ & $9(26)$ & $8(25)$ & $6(24)$ & $9(28)$ & $39(25)$ \\
\hline \multicolumn{7}{|l|}{ Smoking } \\
\hline NO & $32(97)$ & $35(100)$ & $32(100)$ & $25(100)$ & $30(94)$ & 154(98) \\
\hline YES & 1(3) & $0(0)$ & $0(0)$ & $0(0)$ & $2(6)$ & $3(2)$ \\
\hline \multicolumn{7}{|l|}{ Passive Smoking } \\
\hline NO & $20(61)$ & 19(54) & $15(47)$ & $13(52)$ & $17(53)$ & $84(54)$ \\
\hline YES & $12(36)$ & $15(43)$ & $16(50)$ & $10(40)$ & $13(41)$ & $66(42)$ \\
\hline$N A^{c}$ & $1(3)$ & 1(3) & $1(3)$ & $2(8)$ & $2(6)$ & $7(4)$ \\
\hline \multicolumn{7}{|l|}{ Drinking-white } \\
\hline NO & $33(100)$ & $34(97)$ & $30(94)$ & $25(100)$ & $30(94)$ & 152(97) \\
\hline YES & $0(0)$ & $1(3)$ & $2(6)$ & $0(0)$ & $2(6)$ & $5(3)$ \\
\hline \multicolumn{7}{|l|}{ Drinking-beer } \\
\hline Never & $28(85)$ & 19(54) & $14(44)$ & $21(84)$ & $25(78)$ & 107(68) \\
\hline$<1 /$ week & $5(15)$ & $16(46)$ & $17(53)$ & $4(16)$ & $5(16)$ & $47(30)$ \\
\hline $1 \sim 3 /$ week & $0(0)$ & $0(0)$ & $0(0)$ & $0(0)$ & $2(6)$ & $2(1)$ \\
\hline$>3 /$ week & $0(0)$ & $0(0)$ & $1(3)$ & $0(0)$ & $0(0)$ & $1(1)$ \\
\hline \multicolumn{7}{|l|}{ Exercise } \\
\hline$<1 /$ week & $23(70)$ & $23(66)$ & $22(69)$ & $18(72)$ & $20(62)$ & $106(68)$ \\
\hline $1 \sim 3 /$ week & $3(9)$ & $5(14)$ & $5(16)$ & $3(12)$ & $8(25)$ & $24(15)$ \\
\hline$>3 /$ week & $7(21)$ & $7(20)$ & $5(16)$ & $4(16)$ & $4(12)$ & $27(17)$ \\
\hline \multicolumn{7}{|c|}{${ }^{a}$ Data are presented as the mean (standard deviation). } \\
\hline \multicolumn{7}{|c|}{${ }^{\mathrm{b}}$ Data are presented as the number of subjects (percentage). } \\
\hline${ }^{\mathrm{c}}$ Missing data. & & & & & & \\
\hline
\end{tabular}

Association Between PM 2.5 Exposure and Blood Pressure

Across all five visits, the mean (standard deviation) systolic and diastolic blood pressures were 116.3 (14.4) and 75.1 (10.8) $\mathrm{mmHg}$, respectively (Additional file 1: Table S1). For all 35 women, relatively higher mean $\mathrm{PM}_{2.5}$ concentrations were observed during the first, second, and fourth visits, followed by the third and fifth visits (Fig. 1). A similar trend was observed for blood pressure. Overall, $\mathrm{PM}_{2.5}$ concentrations across all five visits were $>100 \mu \mathrm{g} / \mathrm{m}^{3}$, which is higher than the national annual standard of $35 \mu \mathrm{g} / \mathrm{m}^{3}$. 
Three models were constructed to investigate the relationship between $\mathrm{PM}_{2.5}$ and blood pressure (Fig. 2). The univariate model indicated that higher $\mathrm{PM}_{2.5}$ concentrations were associated with elevated systolic and diastolic blood pressures, except for Lag-1 concentrations. After adjustments for potential confounders due to population characteristics and lifestyle habits (i.e., age, body mass index, location, occupation, education, smoking, passive smoking, alcohol consumption, and exercise), similar results were obtained. However, after addition of outdoor temperature into the model, only Lag-7, Lag-30, and Lag-60 $\mathrm{PM}_{2.5}$ concentrations were positively associated with blood pressure. Detailed results are provided in Additional file 1: Table S2.

Model-I: $B P=\beta_{1} \times P M_{2.5}+\gamma(S)$

Model-II: $B P=\beta_{1} \times P M_{2.5}+\beta_{2-11} \times C F_{1-10}+\gamma(S)$

Model-III: $B P=\beta_{1} \times P M_{2.5}+\beta_{2-12} \times C F_{1-11}+\gamma(S)$

The model incorporated fixed terms with coefficients of $\beta_{1}$ of $\mathrm{PM}_{2.5}, \beta_{2-11}$ of potential confounders $\left(C F_{1-10}\right.$, i.e. age, $B M I$, location, occupation, education, smoking, passive smoking, drinking wine or beer and exercise; $C F_{11}$ : ambient temperature), as well as a random intercept each subject $\gamma(S)$. The data were shown with the estimated value with $95 \%$ confidence interval. The $\mathrm{PM}_{2.5}$ concentration were assessed according to subject's addresses by a spatiotemporal model, which fused monitoring data with satellite measurements and chemical transport model simulations.

Associations Between $\mathrm{PM}_{2.5}$ and Serum Metal(loid)s

In total, 13 trace metal(loid)s were measured with a $100 \%$ detection rate, except for $\mathrm{Pb}$, with a detection rate of 96\% (Additional file 1: Table S3). The associations with $\mathrm{PM}_{2.5}$ exposure varied according to lag day and the type of potential confounders used in the model (Table 2 and Additional file 1: Table S4). Serum Mn concentration was positively associated with Lag-7, Lag-30, and Lag-60 $\mathrm{PM}_{2.5}$ concentrations with or without adjustments for population characteristics and lifestyle habits; serum As was positively associated with Lag-1, Lag-3, and Lag-7 concentrations. $\mathrm{PM}_{2.5}$ concentrations were consistently negatively associated with serum $\mathrm{Ni}$ and $\mathrm{Cr}$ concentrations based on the model with adjustments for all confounders; serum Sn was negatively associated with Lag-1, Lag-3, and Lag-60 concentrations. The largest changes in metal(loid) concentration per IQR increase in mean $\mathrm{PM}_{2.5}$ concentration were 12.1\% for Mn (Lag-30), -30.0\% for Ni (Lag-60), -13.8\% for Sn (Lag-1), 39.0\% for $\mathrm{Cr}$ (Lag-30), and 4.42\% for As (Lag-3). Cu, Zn, Fe, Mo, Pb, and Cd were not significantly associated with $\mathrm{PM}_{2.5}$ exposure; Co and Se were only significantly associated with Lag-1 PM 2.5 concentrations. 
Table 2

Associations between outdoor $\mathrm{PM}_{2.5}$ and serum metal(loid)s among the recruited 35 women in North China

\begin{tabular}{|c|c|c|c|c|c|c|c|c|c|c|c|c|}
\hline & Lag-1 & & Lag - & & Lag - & & Lag - & & Lag - & & Lag - & \\
\hline & $\begin{array}{l}P C \\
(\%)^{b}\end{array}$ & $P$ & $\begin{array}{l}P C \\
(\%)\end{array}$ & $P$ & $\begin{array}{l}P C \\
(\%)\end{array}$ & $P$ & $\begin{array}{l}P C \\
\text { (\%) }\end{array}$ & $P$ & $\begin{array}{l}P C \\
\text { (\%) }\end{array}$ & $P$ & $\begin{array}{l}P C \\
(\%)\end{array}$ & $P$ \\
\hline $\mathrm{Cu}^{\mathrm{c}}$ & 3.50 & 0.119 & 2.68 & 0.268 & 0.94 & 0.662 & 0.54 & 0.829 & 0.14 & 0.959 & 1.01 & 0.695 \\
\hline $\mathrm{Zn}$ & 0.02 & 0.995 & 1.04 & 0.707 & 0.84 & 0.732 & 2.00 & 0.489 & 1.28 & 0.675 & 0.52 & 0.858 \\
\hline $\mathrm{Mn}$ & 2.64 & 0.553 & 7.76 & 0.110 & 10.1 & 0.019 & 9.25 & 0.068 & 12.1 & 0.026 & 11.9 & 0.021 \\
\hline $\mathrm{Fe}$ & -6.45 & 0.380 & 0.41 & 0.960 & 2.42 & 0.742 & 8.12 & 0.357 & 3.93 & 0.670 & 2.60 & 0.767 \\
\hline Co & -5.82 & 0.011 & -3.82 & 0.132 & -1.83 & 0.423 & -0.30 & 0.910 & -1.69 & 0.554 & -2.86 & 0.293 \\
\hline $\mathrm{Ni}$ & -22.8 & 0.001 & -26.4 & $\stackrel{<}{<.001}$ & -22.2 & 0.001 & -25.2 & 0.001 & -28.2 & $\begin{array}{l}< \\
0.001\end{array}$ & -30.0 & $\begin{array}{l}< \\
0.001\end{array}$ \\
\hline Mo & -2.12 & 0.431 & -2.05 & 0.481 & -3.56 & 0.161 & -1.32 & 0.663 & -3.80 & 0.231 & -3.50 & 0.249 \\
\hline $\mathrm{Se}$ & 4.12 & 0.049 & 3.49 & 0.123 & 2.29 & 0.253 & 1.02 & 0.663 & 1.61 & 0.521 & 2.18 & 0.363 \\
\hline Sn & -13.8 & 0.002 & -13.2 & 0.006 & -8.56 & 0.055 & -9.14 & 0.079 & -9.69 & 0.079 & -13.1 & 0.011 \\
\hline $\mathrm{Cr}$ & -33.5 & 0.002 & -37.6 & 0.001 & -34.9 & 0.001 & -33.7 & 0.007 & -39.0 & 0.002 & -38.5 & 0.001 \\
\hline $\mathrm{Pb}$ & 13.1 & 0.387 & 2.85 & 0.855 & -4.34 & 0.745 & -14.0 & 0.342 & -12.0 & 0.450 & -6.96 & 0.656 \\
\hline As & 3.58 & 0.029 & 4.42 & 0.012 & 3.63 & 0.021 & 3.22 & 0.082 & 3.48 & 0.077 & 3.45 & 0.066 \\
\hline $\mathrm{Cd}$ & -4.78 & 0.239 & -6.44 & 0.136 & -6.26 & 0.102 & -5.39 & 0.234 & -7.62 & 0.107 & -9.26 & 0.037 \\
\hline
\end{tabular}

${ }^{a}$ Mean concentration of $\mathrm{PM}_{2.5}$ in the $N$ days before the visit time, i.e. $1,3,7,15,30$, and 60 days.

${ }^{\mathrm{b}}$ Estimate percentage changes of metal(loid)s per IQR increase of mean $\mathrm{PM}_{2.5}$ concentration using the linear mixed-effects model: $\log _{10} M=\beta_{1} \times \mathrm{PM}_{2.5}+\beta_{2-11} \times C F_{1-10}+\gamma(S)$, then $\left.\left.P C=\left(10^{\operatorname{lQR}(\mathrm{PM}}{ }_{2.5}\right) \times \beta 1\right)-1\right) \times 100 \%$. The model incorporated fixed terms with coefficients of $\beta_{1}$ to model the effects of $\mathrm{PM}_{2.5}, \beta_{2-11}$ of potential confounders ( $\mathrm{CF}_{1-10}$, i.e. age, BMI, location, occupation, education, smoking, passive smoking, drinking wine or beer, and exercise), as well as a random intercept each subject $\gamma(\mathrm{S})$.

c The abbreviations of the concerned metal(loid)s were Copper (Cu), zinc ( $\mathrm{Zn})$, manganese (Mn), iron (Fe), cobalt (Co), nickel (Ni), molybdenum (Mo), selenium (Se), stannum (Sn), chromium (Cr), lead (Pb), arsenic (As), and cadmium (Cd)

\section{Associations between Serum Metal(loid)s and Blood Pressure}

We further analyzed the associations between serum metal(loid)s and blood pressure. Only serum Mo was associated with systolic blood pressure, when using a linear mixed-effects model adjusted for population characteristics and lifestyle habits. A reduction in systolic blood pressure by $3.16 \mathrm{mmHg}$ was associated with an IQR increase in Mo. No significant associations were observed between other metal(loid)s and blood pressure (Table 3 and Additional file 1: Table S5). 
Table 3

Associations between serum metal(loid)s and blood pressure among the recruited 35 women in North China using Model-II

\begin{tabular}{|c|c|c|c|c|}
\hline \multirow[b]{2}{*}{ Metal(loid)s ${ }^{a}$} & \multicolumn{2}{|c|}{ Systolic blood pressure } & \multicolumn{2}{|c|}{ Diastolic blood pressure } \\
\hline & $\beta_{1}{ }^{b}$ & $P$ & $\beta_{1}$ & $P$ \\
\hline $\mathrm{Cu}$ & -0.67 & 0.699 & 0.35 & 0.790 \\
\hline $\mathrm{Zn}$ & 0.44 & 0.722 & -0.50 & 0.592 \\
\hline $\mathrm{Mn}$ & 0.10 & 0.675 & -0.01 & 0.956 \\
\hline $\mathrm{Fe}$ & 0.50 & 0.411 & -0.12 & 0.791 \\
\hline Co & -0.67 & 0.730 & -0.10 & 0.948 \\
\hline $\mathrm{Ni}$ & -1.00 & 0.108 & -0.19 & 0.685 \\
\hline Mo & -3.16 & 0.018 & -2.00 & 0.054 \\
\hline $\mathrm{Se}$ & -0.59 & 0.703 & -0.94 & 0.426 \\
\hline Sn & -0.93 & 0.386 & -0.16 & 0.848 \\
\hline $\mathrm{Cr}$ & -0.08 & 0.497 & -0.05 & 0.721 \\
\hline $\mathrm{Pb}$ & -0.29 & 0.183 & -0.12 & 0.854 \\
\hline As & 1.66 & 0.173 & 0.18 & 0.314 \\
\hline $\mathrm{Cd}$ & 0.75 & 0.425 & 0.12 & 0.867 \\
\hline \multicolumn{5}{|c|}{$\begin{array}{l}\text { a The abbreviations of the concerned metal(loid)s were Copper }(\mathrm{Cu}) \text {, zinc }(\mathrm{Zn}) \text {, manganese }(\mathrm{Mn}) \text {, iron (Fe), } \\
\text { cobalt (Co), nickel (Ni), molybdenum (Mo), selenium (Se), stannum (Sn), chromium (Cr), lead (Pb), arsenic } \\
\text { (As), and cadmium (Cd) }\end{array}$} \\
\hline \multicolumn{5}{|c|}{$\begin{array}{l}\text { b Estimate blood pressure changes ( } \mathrm{mmHg} \text { ) per IQR increase of metal(loid)s }(\mathrm{M}) \text { using the linear mixed- } \\
\text { effects model: } B P=\beta_{1} \times M+\beta_{2-11} \times C F_{1-10}+\gamma(S) \text {. The model incorporated fixed terms with coefficients of } \beta_{1} \\
\text { of } M, \beta_{2-11} \text { of potential confounders }\left(C F_{1-10} \text {, i.e. age, BMl, location, occupation, education, smoking, passive }\right. \\
\text { smoking, drinking wine or beer, and exercise), as well as a random intercept each subject } \gamma(S) \text {. }\end{array}$} \\
\hline
\end{tabular}

\section{Discussion}

Our study included a group of local women of childbearing age in northern China; multiple follow-ups were conducted to explore the potential involvement of serum metal(loid)s in the relationship between $\mathrm{PM}_{2.5}$ and blood pressure. Overall, systolic and diastolic blood pressures were positively associated with ambient $\mathrm{PM}_{2.5}$ exposure after adjustments for important confounders. In addition, serum concentrations of the metal(loid)s $\mathrm{Mn}, \mathrm{Ni}, \mathrm{Sn}, \mathrm{Cr}$, and As were associated with $\mathrm{PM}_{2.5}$ exposure. However, with the exception of Mo, no significant associations were observed between serum concentrations of the other metal(loid)s and blood pressure. In general, our results indicate that $\mathrm{PM}_{2.5}$ pollution may have adverse effects on blood pressure in adult women; these effects may be mediated by the intake of various metal(loid)s. 
Our study mainly focused on women of childbearing age and demonstrated the potential adverse effects of $\mathrm{PM}_{2.5}$ on blood pressure in this population. The study area experiences relatively high $\mathrm{PM}_{2.5}$ pollution. The average outdoor $\mathrm{PM}_{2.5}$ concentration over the five visits was $>100 \mu \mathrm{g} / \mathrm{m}^{3}$, which is significantly higher than the national annual standard of $75 \mu \mathrm{g} / \mathrm{m}^{3}$ in China. Furthermore, this concentration is higher than concentrations observed in other provinces in China, as well as concentrations observed in the USA, Brazil, and the Netherlands $[27,28,29,30,31,32]$. We found that $\mathrm{PM}_{2.5}$ was positively associated with both systolic and diastolic blood pressures after adjustments for the main confounders, with or without including ambient temperature. Similar results were also obtained in a cross-sectional study of 39 million adults of childbearing age in China [33]. To the best of our knowledge, there have been few other studies regarding the effects of $\mathrm{PM}_{2.5}$ on blood pressure in women of childbearing age. The associations between $\mathrm{PM}_{2.5}$ exposure and systolic and diastolic blood pressures have been widely reported for other populations, but the results of these studies have been inconsistent. Some studies indicated that ambient $\mathrm{PM}_{2.5}$ exposure was positively associated with both systolic and diastolic blood pressures [6, 34], whereas others reported that $\mathrm{PM}_{2.5}$ exposure was only positively associated with systolic blood pressure $[35,36,37,38]$. A number of studies have also found that $\mathrm{PM}_{2.5}$ exposure was not significantly associated with either systolic or diastolic blood pressures [27, 30, 39]. This inconsistency could have multiple sources, such as study design, $\mathrm{PM}_{2.5}$ exposure level, sample size, and participant characteristics. Our study had a repeated-measurement design, which involved five visits. In most other repeated-measurement studies, the participants received two to four visits [36, 40,41]. Likewise, in previous studies, the intervals between surveys were shorter than 2 weeks $[42,43]$; in our study, the intervals between surveys were several months in length. $\mathrm{PM}_{2.5}$ concentrations fluctuated greatly between any two consecutive visits. Hence, we were able to investigate the effects of $\mathrm{PM}_{2.5}$ exposure on blood pressure in the study population, as well as any lag effects related to $\mathrm{PM}_{2.5}$ exposure. For example, the difference in $\mathrm{PM}_{2.5}$ concentrations between the first and third surveys was $>100 \mu \mathrm{g} / \mathrm{m}^{3}$, which is much larger than the changes reported in other repeated-measurement studies [40,43]. However, our study included only 35 women; thus, the study had fewer participants than other similar studies. This may have affected the reliability of the doseresponse analysis.

Both organic and inorganic components of $\mathrm{PM}_{2.5}$ may contribute to the adverse effects of $\mathrm{PM}_{2.5}$ on blood pressure. Polycyclic aromatic hydrocarbons, organic constituents of $\mathrm{PM}_{2.5}$, are reportedly not significantly associated with the risk of hypertension $[44,45]$. Thus, our study focused mainly on inorganic metal(loid) components, because their associations with blood pressure are well-known $[19,20]$. In northern China, metal elements comprise a large proportion of $\mathrm{PM}_{2.5}[9,10,11]$. Inhalable particulate matter may be an important exposure route by which many metals enter the body [46]. Therefore, it is important to investigate how the inorganic components of $\mathrm{PM}_{2.5}$ affect blood pressure stability. Here, we found that $\mathrm{PM}_{2.5}$ concentration was significantly correlated with some serum metal(loid)spositively with serum Mn and As, and negatively with serum $\mathrm{Ni}, \mathrm{Sn}$, and $\mathrm{Cr}$. Our previous study revealed that indoor air pollution level was associated with hair metal(loid) concentrations (positively with As and Pb, and negatively with $\mathrm{Ni}, \mathrm{Sn}, \mathrm{Cr}$, and $\mathrm{Co}$ ) in women in Shanxi Province, China [12]. However, a study conducted in Wuhan did not find any significant associations between urinary metal contents and $\mathrm{PM}_{2.5}$ exposure [25]. The relationships between $\mathrm{PM}_{2.5}$ exposure and internal metal(loid) concentrations can vary with location, $\mathrm{PM}_{2.5}$ concentration, lifestyle, exposure biomarkers, and other factors. Compared with other biomarkers, serum metal(loid)s can indicate recent exposure (days) in a 
population and have been used as exposure biomarkers in previous studies [47, 48]. Although diet is the main intake route for various metal(loid)s [46], it was not considered in our study. Hence, additional in-depth studies are needed to confirm our findings.

Toxicity patterns associated with nutrients and toxic metals vary. For essential trace metals, toxic effects usually occur when their exposure levels are above or below their acceptable ranges. For toxic metals, toxic effects on blood pressure usually increase linearly with their exposure concentrations, especially when the exposure levels are above threshold levels $[16,19]$. Our study findings indicate that $\mathrm{PM}_{2.5}$ may interfere with the balance of trace elements in the body by enhancing the levels of toxic metals and reducing the levels of nutrient elements. However, we did not find a strong relationship between serum metal(loid)s and blood pressure. Possible explanations are that the serum concentrations of various metal(loid)s do not represent long-term exposure levels, or that they are subject to lag effects, which were not investigated in our study. Another explanation is that $\mathrm{PM}_{2.5}$ may induce blood vessel injuries via other pathways, such that the effects of internal metal(loid) intake are negligible. To the best of our knowledge, there is little evidence that internal metal(loid) intake contributes to the association between $\mathrm{PM}_{2.5}$ and blood pressure. Further research is needed to clarify the results obtained in this study.

Our study had two important limitations. First, the metal(loid) contents in outdoor $\mathrm{PM}_{2.5}$ were not measured, and the quantities inhaled by the participants could not be determined. Second, the effects of dietary foods were not considered. However, we were able to reveal the impact of $\mathrm{PM}_{2.5}$ on blood pressure and the potential involvement of metal(loid)s. $\mathrm{PM}_{2.5}$ concentrations during our study period were relatively high and varied greatly over the five visits; thus, we could investigate the effects of high levels of $\mathrm{PM}_{2.5}$ exposure on blood pressure. Because we adopted a repeated-measurement design, we effectively reduced the influences of some confounding factors. Furthermore, by collecting serum samples, we were able to characterize population internal exposure to $\mathrm{PM}_{2.5}$.

\section{Conclusions}

To the best of our knowledge, this is the first study to investigate whether internal metal(loid)s are involved in the association between outdoor $\mathrm{PM}_{2.5}$ concentration and blood pressure by using multiple follow-ups in northern China. For our study population, we conclude that greater $\mathrm{PM}_{2.5}$ exposure was associated with elevated blood pressure, perhaps due to an imbalance of internal metal(loid)s. Our results help to illuminate the adverse health effects of $\mathrm{PM}_{2.5}$ on human blood pressure.

\section{Declarations}

\section{Ethics approval and consent to participate}

Our study protocol was approved by the institutional review board of Peking University, and written informed consent was obtained from all participants.

\section{Consent for publication}


Not applicable

\section{Availability of data and materials}

The datasets during and/or analysed during the current study are available from the corresponding author on reasonable request.

\section{Competing interests}

All authors declare they have no actual or potential competing financial interests.

\section{Funding}

This work was supported by the National Natural Science Foundation of China [Grant No. 41401583, 41771527, and 81673177].

\section{Authors' contributions}

B.W., Y.Y. and C.L. conceived the study. T.X. obtained PM2.5 concentration data. C.L. perform the analysis and wrote the first draft of the manuscript. L.Q., B.W., B.J., S.G., X.W., M.G., Y.Y., X.Z. and Z.L. participated the study design, sample collection and analysis. L.Q., B.W., T.X., J.C., B.J., S.G., X.W., M.G., Y.Y., Y.X, X.Z. and Z.L. reviewed and edited the manuscript. B.W. and Y.Y. managed the program. All the authors read and approved the final manuscript.

\section{Acknowledgement}

All authors would like to express our gratitude to the help from the working group of environmental exposure and human health of the China Cohort Consortium (See http://chinacohort.bjmu.edu.cn/).

\section{References}

1. Estimates and 25-year trends of the global burden of disease attributable to ambient air pollution: an analysis of data from the Global Burden of Diseases Study 2015

10.1016/s0140-6736(17)30505-6

Cohen AJ, Brauer M, Burnett R, Anderson HR, Frostad J, Estep K, et al. Estimates and 25-year trends of the global burden of disease attributable to ambient air pollution: an analysis of data from the Global Burden of Diseases Study 2015. The Lancet. 2017;389 10082:1907-18; doi:10.1016/s0140-6736(17)30505-6.

2. Chen R, Zhao A, Chen H, Zhao Z, Cai J, Wang C, et al. Cardiopulmonary benefits of reducing indoor particles of outdoor origin: a randomized, double-blind crossover trial of air purifiers. J Am Coll Cardiol. 2015;65 21:2279-87; doi:10.1016/j.jacc.2015.03.553. https://www.ncbi.nlm.nih.gov/pubmed/26022815.

3. Aaron CP, Chervona Y, Kawut SM, Diez Roux AV, Shen M, Bluemke DA, et al. Particulate Matter Exposure and Cardiopulmonary Differences in the Multi-Ethnic Study of Atherosclerosis. Environ Health Perspect. 2016;124 8:1166-73. doi:10.1289/ehp.1409451. 
4. Zhang H, Qian J, Zhao H, Wang J, Zhu H, Zhou Y, et al. A study of the association between atmospheric particulate matter and blood pressure in the population. Blood Press 2016;25 3:169-76;

doi:10.3109/08037051.2015.1111019. https://www.ncbi.nlm.nih.gov/pubmed/26634767.

5. Lee PC, Talbott EO, Roberts JM, Catov JM, Bilonick RA, Stone RA, et al. Ambient air pollution exposure and blood pressure changes during pregnancy. Environ Res 2012;117:46-53; doi:10.1016/j.envres.2012.05.011. https://www.ncbi.nlm.nih.gov/pubmed/22835955.

6. Zhang Z, Guo C, Lau AKH, Chan TC, Chuang YC, Lin C, et al. Long-Term Exposure to Fine Particulate Matter, Blood Pressure, and Incident Hypertension in Taiwanese Adults. Environ Health Perspect. 2018;126 1:017008; doi:10.1289/EHP2466. https://www.ncbi.nlm.nih.gov/pubmed/29351544.

7. Chen H, Burnett RT, Kwong JC, Villeneuve PJ, Goldberg MS, Brook RD, et al. Spatial association between ambient fine particulate matter and incident hypertension. Circulation. 2014;129 5:562-9. doi:10.1161/circulationaha.113.003532.

8. Fuks KB, Weinmayr G, Basagaña X, Gruzieva O, Hampel R, Oftedal B, et al. Long-term exposure to ambient air pollution and traffic noise and incident hypertension in seven cohorts of the European study of cohorts for air pollution effects (ESCAPE). European heart journal. 2017;38 13:983-90.

doi:10.1093/eurheartj/ehw413.

9. Wang B, Li N, Deng F, Buglak N, Park G, Su S, et al. Human bronchial epithelial cell injuries induced by fine particulate matter from sandstorm and non-sandstorm periods: Association with particle constituents. J Environ Sci (China). 2016;47:201-10; doi:10.1016/j.jes.2015.12.015. https://www.ncbi.nlm.nih.gov/pubmed/27593287.

10. Wang B, Li K, Jin W, Lu Y, Zhang Y, Shen G, et al. Properties and inflammatory effects of various size fractions of ambient particulate matter from Beijing on A549 and J774A.1 cells. Environ Sci Technol. 2013;47 18:10583-90; doi:10.1021/es401394g. https://www.ncbi.nlm.nih.gov/pubmed/23957470.

11. Wu S, Yang D, Wei H, Wang B, Huang J, Li H, et al. Association of chemical constituents and pollution sources of ambient fine particulate air pollution and biomarkers of oxidative stress associated with atherosclerosis: A panel study among young adults in Beijing, China. Chemosphere. 2015;135:347-53. doi:10.1016/j.chemosphere.2015.04.096.

12. Lu X, Ye Z, Zheng S, Ren H, Zeng J, Wang X, et al. Long-Term Exposure of Fine Particulate Matter Causes Hypertension by Impaired Renal $D_{1}$ Receptor-Mediated Sodium Excretion via Upregulation of G-ProteinCoupled Receptor Kinase Type 4 Expression in Sprague-Dawley Rats. Journal of the American Heart Association. 2018;7 1; doi:10.1161/jaha.117.007185.

13. Wu W, Jiang S, Zhao Q, Zhang K, Wei X, Zhou T, et al. Associations of environmental exposure to metals with the risk of hypertension in China. Sci Total Environ. 2018;622-623:184 - 91; doi: 10.1016/j.scitotenv.2017.11.343. https://www.ncbi.nlm.nih.gov/pubmed/29216461.

14. Dai L, Koutrakis P, Coull BA, Sparrow D, Vokonas PS, Schwartz JD. Use of the Adaptive LASSO Method to Identify PM2.5 Components Associated with Blood Pressure in Elderly Men: The Veterans Affairs Normative Aging Study. Environ Health Perspect. 2016;124(1):120-5. doi:10.1289/ehp.1409021.

15. Navas-Acien A, Guallar E, Silbergeld EK, Rothenberg SJ. Lead exposure and cardiovascular disease-a systematic review. Environ Health Perspect. 2007;115 3:472-82; doi:10.1289/ehp.9785. https://www.ncbi.nlm.nih.gov/pubmed/17431501. 
16. Cosselman KE, Navas-Acien A, Kaufman JD. Environmental factors in cardiovascular disease. Nat Rev Cardiol. 2015;12 11:627-42; doi:10.1038/nrcardio.2015.152.

https://www.ncbi.nlm.nih.gov/pubmed/26461967.

17. da Cunha Martins A Jr, Carneiro MFH, Grotto D, Adeyemi JA, Barbosa F. Jr. Arsenic, cadmium, and mercuryinduced hypertension: mechanisms and epidemiological findings. J Toxicol Environ Health B Crit Rev.

2018;21 2:61-82; doi:10.1080/10937404.2018.1432025.

https://www.ncbi.nlm.nih.gov/pubmed/29446707.

18. Bulka CM, Scannell Bryan M, Persky VW, Daviglus ML, Durazo-Arvizu RA, Parvez F, et al. Changes in blood pressure associated with lead, manganese, and selenium in a Bangladeshi cohort. Environ Pollut.

2019;248:28-35. doi:10.1016/j.envpol.2019.01.129.

19. Loyke HF. Effects of elements on blood pressure. Biological trace element research. 1997;581-2:1-12; doi: 10.1007/bf02910661.

20. Loyke HF. Effects of elements in human blood pressure control. Biol Trace Elem Res. 2002;85 3:193-209. doi:10.1385/bter:85:3:193.

21. Yue W, Tong L, Liu X, Weng X, Chen X, Wang D, et al. Short term Pm2.5 exposure caused a robust lung inflammation, vascular remodeling, and exacerbated transition from left ventricular failure to right ventricular hypertrophy. Redox biology. 2019;22:101161. doi:10.1016/j.redox.2019.101161.

22. Dutta A, Ray MR, Banerjee A. Systemic inflammatory changes and increased oxidative stress in rural Indian women cooking with biomass fuels. Toxicol Appl Pharmcol. 2012;261 3:255-62. doi:10.1016/j.taap.2012.04.004.

23. Valko M, Morris H, Cronin MT. Metals, toxicity and oxidative stress. Curr Med Chem. 2005;12 10:1161-208. doi:10.2174/0929867053764635.

24. Jomova K, Valko M. Advances in metal-induced oxidative stress and human disease. Toxicology. 2011;283(2-3):65-87. doi:10.1016/j.tox.2011.03.001.

25. Yu YQ, Cui XQ, Feng W, Zhang XM, Yuan J, Chen WH, et al. [Association between personal exposure to metals in fine particulate matter and urinary metals: baseline results from a panel study]. Zhonghua Yu Fang Yi Xue Za Zhi 2016;50 8:673-9; doi:10.3760/cma.j.issn.0253-9624.2016.08.003. https://www.ncbi.nlm.nih.gov/pubmed/27539519.

26. Xue T, Zheng Y, Geng G, Zheng B, Jiang X, Zhang Q, et al. Fusing Observational, Satellite Remote Sensing and Air Quality Model Simulated Data to Estimate Spatiotemporal Variations of PM2.5 Exposure in China. Remote Sensing. 2017;9 3; doi:10.3390/rs9030221.

27. Chung M, Wang DD, Rizzo AM, Gachette D, Delnord M, Parambi R, et al. Association of PNC, BC, and PM2.5 measured at a central monitoring site with blood pressure in a predominantly near highway population. Int J Environ Res Public Health. 2015;12 3:2765-80; doi:10.3390/ijerph120302765. https://www.ncbi.nlm.nih.gov/pubmed/25741638.

28. Lin H, Guo Y, Zheng Y, Di Q, Liu T, Xiao J, et al. Long-Term Effects of Ambient PM2.5on Hypertension and Blood Pressure and Attributable Risk Among Older Chinese Adults. Hypertension. 2017;69 5:806-12. doi:10.1161/hypertensionaha.116.08839.

29. Santos UP, Ferreira Braga AL, Bueno Garcia ML, Amador Pereira LA, Lin CA, Chiarelli PS, et al. Exposure to fine particles increases blood pressure of hypertensive outdoor workers: A panel study. Environ Res. 
2019;174:88-94. doi:10.1016/j.envres.2019.04.021.

30. Bilenko N, Brunekreef B, Beelen R, Eeftens M, de Hoogh K, Hoek G, et al. Associations between particulate matter composition and childhood blood pressure - The PIAMA study. Environ Int. 2015;84:1-6. doi:10.1016/j.envint.2015.07.010.

31. Chen Y, Zang L, Du W, Xu D, Shen G, Zhang Q, et al. Ambient air pollution of particles and gas pollutants, and the predicted health risks from long-term exposure to $\mathrm{PM}(2.5)$ in Zhejiang province, China. Environ Sci Pollut Res Int. 2018;25 24:23833-44. doi:10.1007/s11356-018-2420-5.

32. Sun Z, Yang L, Bai X, Du W, Shen G, Fei J, et al. Maternal ambient air pollution exposure with spatialtemporal variations and preterm birth risk assessment during 2013-2017 in Zhejiang Province, China. Environ Int. 2019. doi:10.1016/j.envint.2019.105242. ;133 Pt B:105242.

33. 10.1161/JAHA.118.008553

Xie X, Wang Y, Yang Y, Xu J, Zhang Y, Tang W, et al. Long-Term Effects of Ambient Particulate Matter (With an Aerodynamic Diameter </=2.5 mum) on Hypertension and Blood Pressure and Attributable Risk Among Reproductive-Age Adults in China. J Am Heart Assoc. 2018;7 9; doi: 10.1161/JAHA.118.008553. https://www.ncbi.nlm.nih.gov/pubmed/29700042.

34. Liang R, Zhang B, Zhao X, Ruan Y, Lian H, Fan Z. Effect of exposure to PM2.5 on blood pressure: a systematic review and meta-analysis. J Hypertens. 2014;32 11:2130-40; discussion 41; doi:10.1097/HJH.0000000000000342. https://www.ncbi.nlm.nih.gov/pubmed/25250520.

35. Soppa VJ, Schins RPF, Hennig F, Nieuwenhuijsen MJ, Hellack B, Quass U, et al. Arterial blood pressure responses to short-term exposure to fine and ultrafine particles from indoor sources - A randomized shamcontrolled exposure study of healthy volunteers. Environ Res. 2017;158:225-32; doi:10.1016/j.envres.2017.06.006. https://www.ncbi.nlm.nih.gov/pubmed/28662448.

36. Yin W, Hou J, Xu T, Cheng J, Wang X, Jiao S, et al. Association of individual-level concentrations and human respiratory tract deposited doses of fine particulate matter with alternation in blood pressure. Environ Pollut. 2017;230:621-31; doi:10.1016/j.envpol.2017.07.006. https://www.ncbi.nlm.nih.gov/pubmed/28710980.

37. Liu C, Chen R, Zhao Y, Ma Z, Bi J, Liu Y, et al. Associations between ambient fine particulate air pollution and hypertension: A nationwide cross-sectional study in China. Sci Total Environ. 2017;584-585:869 - 74; doi: 10.1016/j.scitotenv.2017.01.133. https://www.ncbi.nlm.nih.gov/pubmed/28153400.

38. Honda T, Pun VC, Manjourides J, Suh H. Associations of long-term fine particulate matter exposure with prevalent hypertension and increased blood pressure in older Americans. Environ Res 2018;164:1-8; doi:10.1016/j.envres.2018.02.008. https://www.ncbi.nlm.nih.gov/pubmed/29459230.

39. Chen SY, Wu CF, Lee JH, Hoffmann B, Peters A, Brunekreef B, et al. Associations between Long-Term Air Pollutant Exposures and Blood Pressure in Elderly Residents of Taipei City: A Cross-Sectional Study. Environ Health Perspect. 2015;123 8:779-84; doi:10.1289/ehp.1408771.

https://www.ncbi.nlm.nih.gov/pubmed/25793646.

40. Mu L, Deng F, Tian L, Li Y, Swanson M, Ying J, et al. Peak expiratory flow, breath rate and blood pressure in adults with changes in particulate matter air pollution during the Beijing Olympics: a panel study. Environ Res 2014;133:4-11; doi:10.1016/j.envres.2014.05.006. https://www.ncbi.nlm.nih.gov/pubmed/24906062.

41. Huang W, Wang L, Li J, Liu M, Xu H, Liu S, et al. Short-Term Blood Pressure Responses to Ambient Fine Particulate Matter Exposures at the Extremes of Global Air Pollution Concentrations. Am J Hypertens. 
2018;31 5:590-9; doi:10.1093/ajh/hpx216. https://www.ncbi.nlm.nih.gov/pubmed/29409056.

42. Baccarelli A, Barretta F, Dou C, Zhang X, McCracken JP, Díaz A, et al. Effects of particulate air pollution on blood pressure in a highly exposed population in Beijing, China: a repeated-measure study. Environ Health. 2011;10:108. doi:10.1186/1476-069x-10-108.

43. Ren M, Zhang H, Benmarhnia T, Jalaludin B, Dong H, Wu K, et al. Short-term effects of real-time personal PM2.5 exposure on ambulatory blood pressure: A panel study in young adults. Sci Total Environ.

2019;697:134079; doi:10.1016/j.scitotenv.2019.134079. https://www.ncbi.nlm.nih.gov/pubmed/31484088.

44. Sancini A, Caciari T, Sinibaldi F, Sacco C, Boscolo P, Giubilati R, et al. Blood pressure changes and polycyclic aromatic hydrocarbons in outdoor workers. Clin Ter. 2014;165(4):e295-303. doi:10.7417/ct.2014.1746.

45. Wang B, Li Z, Ma Y, Qiu X, Ren A. Association of polycyclic aromatic hydrocarbons in housewives' hair with hypertension. Chemosphere 2016;153:315-21; doi:10.1016/j.chemosphere.2016.03.067. https://www.ncbi.nlm.nih.gov/pubmed/27023119.

46. 10.1016/j.scitotenv.2009.10.075

Zheng N, Liu J, Wang Q, Liang Z. Health risk assessment of heavy metal exposure to street dust in the zinc smelting district, Northeast of China. Sci Total Environ. 2010;408 4:726 - 33; doi:

10.1016/j.scitotenv.2009.10.075. https://www.ncbi.nlm.nih.gov/pubmed/19926116.

47. Yu Y, Gao M, Wang X, Guo Y, Pang Y, Yan H, et al. Recommended acceptable levels of maternal serum typical toxic metals from the perspective of spontaneous preterm birth in Shanxi Province, China. Sci Total Environ. 2019;686:599-605; doi:10.1016/j.scitotenv.2019.05.413.

https://www.ncbi.nlm.nih.gov/pubmed/31185407.

48. 10.1016/j.taap.2018.07.030

Wang H, Li J, Zhang X, Zhu P, Hao JH, Tao FB, et al. Maternal serum arsenic level during pregnancy is positively associated with adverse pregnant outcomes in a Chinese population. Toxicol Appl Pharm. 2018;356:114-9; doi: 10.1016/j.taap.2018.07.030. <Go to ISI>://WOS:000444662600013.

\section{Figures}




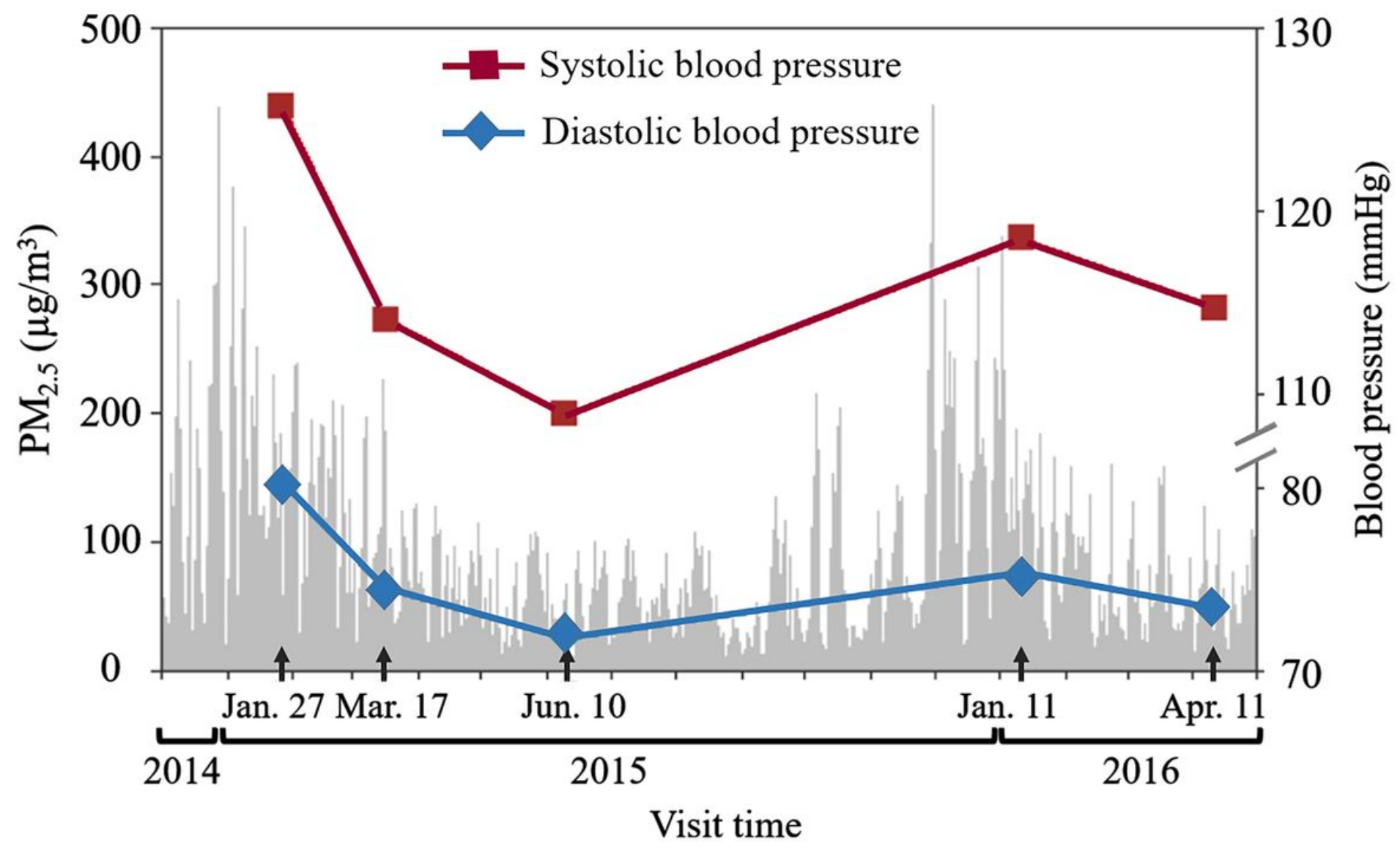

Figure 1

Change trend of the daily average PM2.5 concentration and blood pressure of the 35 women. 

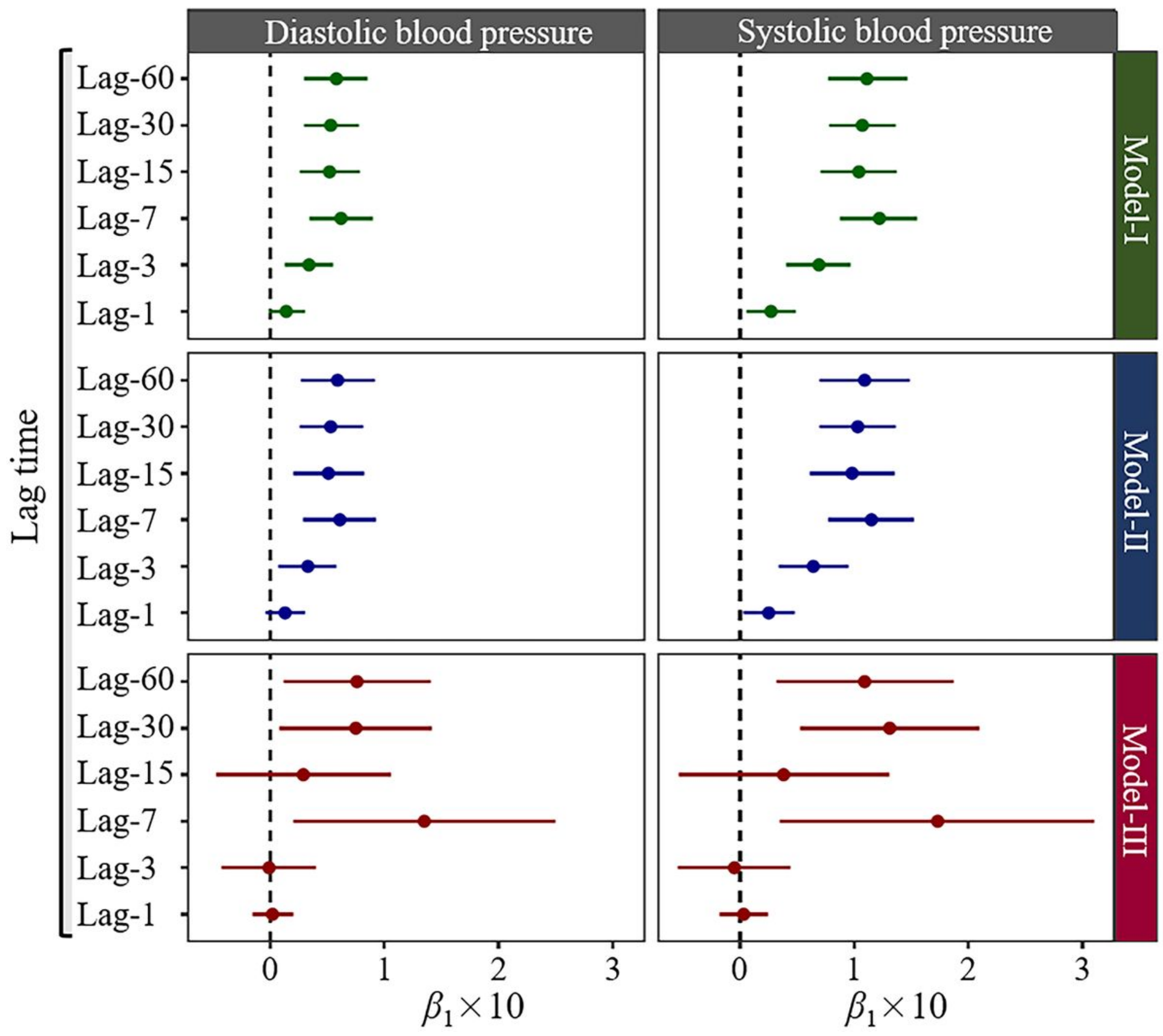

Figure 2

Estimate blood pressure changes $(\mathrm{mmHg})$ per $10 \mu \mathrm{g} / \mathrm{m} 3$ increase of PM2.5 using three linear mixed-effects model as follows: Model-I: $B P=\beta 1 \times P M 2.5+\gamma(S)$ Model-II: $B P=\beta 1 \times P M 2.5+\beta 2-11 \times C F 1-10+\gamma(S)$ Model-III: $B P=$ $\beta 1 \times P M 2.5+\beta 2-12 \times C F 1-11+\gamma(S)$

\section{Supplementary Files}

This is a list of supplementary files associated with this preprint. Click to download.

- Additionalfile1.docx 